\title{
Inverse Magnetocaloric Effects in Metamagnetic Ni-Mn-In-based Alloys in High Magnetic
}

\section{Fields}

Yury Koshkid'ko', Sudip Pandey ${ }^{2}$, Abdiel Quetz ${ }^{2}$, Anil Aryal ${ }^{2}$, Igor Dubenko ${ }^{2}$, Jacek Cwik ${ }^{1}$, Elvina Dilmieva ${ }^{1}$, Alexander Granovsky ${ }^{3}$, E. Lähderanta ${ }^{4}$, A. Zhukov ${ }^{5}$, Shane Stadler ${ }^{6}$, and Naushad $\mathrm{Ali}^{2}$

${ }^{1}$ International Laboratory of High Magnetic Fields and Low Temperatures, Wroclaw 53-421, Poland.

${ }^{2}$ Department of Physics, Southern Illinois University, Carbondale, IL 62901, USA

${ }^{3}$ Faculty of Physics, Lomonosov Moscow State University, Vorob'evy Gory, 11999I Moscow, Russia.

${ }^{4}$ Lappeenranta University of Technology, 53851, Finland.

${ }^{5}$ Dpto. de Física de Materiales, Fac. Químicas, UPV/EHU, 20018, San Sebastian, Spain and IKERBASQUE, Basque Foundation for Science, 48011 Bilbao, Spain.

${ }^{6}$ Department of Physics \& Astronomy, Louisiana State University, Baton Rouge, LA 70803 USA.

\begin{abstract}
Magnetocaloric effects (MCE) in the $\mathrm{Ni}_{50} \mathrm{Mn}_{35} \mathrm{In}_{15}, \quad \mathrm{Ni}_{50.2} \mathrm{Mn}_{34.85} \operatorname{In}_{14.95}$, and $\mathrm{Ni}_{50} \mathrm{Mn}_{35} \mathrm{In}_{14.25} \mathrm{~B}_{0.75}$ Heusler alloys have been studied employing direct measurements of the adiabatic temperature changes $\left(\Delta \mathrm{T}_{\mathrm{ad}}\right)$ using the extraction method with magnetic field changes $(\Delta \mathrm{H})$ up to $14 \mathrm{~T}$, differential scanning calorimetry, and magnetization measurements in magnetic fields up to $14 \mathrm{~T}$. Both the $\Delta \mathrm{T}_{\mathrm{ad}}$ and the entropy changes $(\Delta \mathrm{S})$ values increase as the martensitic transition approaches the Curie temperature of the austenitic phase. The $\Delta \mathrm{T}_{\mathrm{ad}}$ as a function of magnetic field increases up to a maximum value, which depends on the current temperature, and shows a tendency to saturate in high fields. The influence of the rate of magnetic field change and the rate of heating on the $\Delta \mathrm{T}_{\mathrm{ad}}$ of $\mathrm{Ni}_{50} \mathrm{Mn}_{35} \mathrm{In}_{14.25} \mathrm{~B}_{0.75}$ has been studied. It has been shown that an increase in the heating rate from 7 to $23 \mathrm{~K} / \mathrm{min}$ results in an increase of $\Delta \mathrm{T}_{\text {ad }}$ by about $40 \%$ for $\Delta \mathrm{H}=10 \mathrm{~T}$. The effect is discussed in the terms of the influence the heating rate on the nucleation of the austenitic phase. The results on critical magnetic fields for MCE saturation and
\end{abstract}


kinetic effects are applicable to any other system displaying magnetostructural, first-order phase transition.

\section{Introduction}

In recent years, significant progress has been made in understanding magnetostructural transitions (MSTs) and related magneto-responsive phenomena such as magnetocaloric effects (MCE) [1-4], giant magnetoresistance [5], anomalous Hall effects [6] and thermoelectric power [7] observed in the family of Ni-Mn-In-based Heusler alloys. These compounds are of considerable interest as model systems for the study of MCEs in magnetic materials with structural transformations. The alloys have also been identified as promising materials for magnetic refrigeration applications [8].

The MCE resulting from a magnetic field change $(\Delta \mathrm{H})$ is characterized by an isothermal change in the entropy $\Delta \mathrm{S}_{\mathrm{T}}(\mathrm{T}, \Delta \mathrm{H})$, and an adiabatic temperature change $\Delta \mathrm{T}_{\mathrm{ad}}(\mathrm{T}, \Delta \mathrm{H})$. These parameters can be computed from the Maxwell relations:

$$
\begin{aligned}
& \Delta S_{T}(T, \Delta H)=\mu_{0} \int_{0}^{H_{\max }}\left(\frac{\partial M}{\partial T}\right)_{H} d H \\
& \Delta T_{a d}(T, \Delta H)=\mu_{0} \int_{0}^{H_{\max }} \frac{T}{C_{p}(T, H)}\left(\frac{\partial M}{\partial T}\right) d H
\end{aligned}
$$

where $\mathrm{C}_{\mathrm{p}}$ is the specific heat capacity. As far as these two basic parameters of MCE are defined under different thermodynamic conditions (see Eqs.1 and 2) and, additionally, the heat capacity is a function of many factors [9], the connection between $\left.\Delta \mathrm{S}_{\mathrm{T}}(\mathrm{T}, \Delta \mathrm{H})\right)$ and $\Delta \mathrm{T}_{\mathrm{ad}}(\mathrm{T}, \Delta \mathrm{H})$ is not linear in the general case. Therefore, both parameters need to be examined for a thorough MCE description. The Ni-Mn-In based Heusler alloys demonstrating large MCE values are characterized by a rather low magnetization of about 30-60 emu/g in the martensitic phase in the ground state $(\mathrm{T}=5 \mathrm{~K})$ compared to saturated one, where $\mathrm{M}_{\mathrm{S}} \sim 100-120 \mathrm{emu} / \mathrm{g}$, and also by high 
temperature metamagnetic transitions to the ferromagnetic (FM) state of the austenitic phase (AP) $[2,5,7]$. The AP magnetization was found to depend on the separation between the MST and $\mathrm{AP} \mathrm{T}_{\mathrm{C}}$ temperatures. It has been shown that the magnetization of the ferromagnetic $\mathrm{AP}(\approx 70$ emu/g at $\mathrm{H}=9 \mathrm{~T}$ ) is somewhat smaller than the saturated value if $\mathrm{T}_{\mathrm{C}}$ is inside the martensitic hysteresis region. [10]. Therefore, strong magnetic fields are required to transform such alloys to the saturated state. Considering that the MST is controlled by phase nucleation and growth processes with different characteristic times [1,2], and also by complex kinetic relaxation dynamics [3], the study of the MCE using strong permanent magnetic fields and the sample extraction method can be employed as an effective alternative to the pulsed magnetic field method $[1,4,9,11]$. The extraction method provides the opportunity to apply uniform magnetic fields in a larger volume, and with longer exposure times and variable speeds of field application. It should also be noted here that the most reliable $\Delta \mathrm{T}_{\text {ad }}$ values at MSTs can only be obtained by direct methods [12].

The total/isothermal entropy changes $\Delta \mathrm{S}_{\mathrm{t}} / \Delta \mathrm{S}_{\mathrm{T}}$ at the MST in Ni-Mn-In based alloys were found to increase with increasing MST temperature [2]. The total entropy reaches maximum values close to $T_{C}$ and remains nearly constant if $T_{C}$ lies in the MST hysteresis region. In contrast, the $\Delta \mathrm{T}_{\mathrm{ad}}$ values obtained from direct measurements do not show such a tendency [10, $13,14]$. Such behaviors of the $\Delta \mathrm{T}_{\text {ad }}$ can be explained by the likelihood that the magnetic fields used in the Ref. $[10,13,14]$ were not strong enough to complete the MST.

In this work, we report the results of MCE studies carried out using the extraction method with magnetic fields up to $14 \mathrm{~T}$ with a focus on the field dependence of $\Delta \mathrm{T}_{\mathrm{ad}}$ and the role of the thermomagnetic prehistory. The samples from the Ni-Mn-In-based family with different MST temperatures relative to the $\mathrm{T}_{\mathrm{C}}$ of the AP have been chosen for this study. The motivation for 
selecting $\mathrm{Ni}_{50} \mathrm{Mn}_{35} \mathrm{In}_{14.25} \mathrm{~B}_{0.75}$ for the current study were the significant differences between Tc and the temperature of the MST on heating (60 K difference) and cooling (79K difference) [14].

\section{Experimental details}

Samples of $\mathrm{Ni}_{50} \mathrm{Mn}_{35} \mathrm{In}_{15}, \mathrm{Ni}_{50.2} \mathrm{Mn}_{34.85} \operatorname{In}_{14.95}$, and $\mathrm{Ni}_{50} \mathrm{Mn}_{35} \operatorname{In}_{14.25} \mathrm{~B}_{0.75}$ were fabricated by conventional arc-melting in a high-purity argon atmosphere using $4 \mathrm{~N}$ purity elements and were subsequently annealed in high vacuum $\left(\sim 10^{-4}\right.$ Torr $)$ for $24 \mathrm{~h}$ at $850^{\circ} \mathrm{C}$. Considering that the mass losses during arc-melting results from the loss of manganese, an appreciable amount of excess Mn has been added to assure that the $\mathrm{Ni}_{50} \mathrm{Mn}_{35} \mathrm{In}_{15}$ and $\mathrm{Ni}_{50} \mathrm{Mn}_{35} \mathrm{In}_{14.25} \mathrm{~B}_{0.75}$ alloys were very close to their nominal compositions. The nominal composition of the $\mathrm{Ni}_{50.2} \mathrm{Mn}_{34.85} \operatorname{In}_{14.95}$ sample has been calculate taking into account the $1 \mathrm{wt} . \% \mathrm{Mn}$ loss observed for this sample. The phase purities of the compounds were confirmed by $\mathrm{x}$-ray powder diffraction at room temperature using CuKa radiation. Differential scanning calorimetry (DSC) measurements were carried out employing a Perkin-Elmer DSC 8000 instrument (with a ramp rate of $20 \mathrm{~K} / \mathrm{min}$ during heating and cooling) in the temperature range of $123-473 \mathrm{~K}$. The total change of the entropy, $\Delta \mathrm{S}_{\mathrm{t}}$, resulting from the MST at zero magnetic field was estimated from the endothermic peaks of the heat flow curves of the DSC using $\Delta S_{t}=\int_{T_{S}}^{T_{F}}(T)^{-1} * \frac{d Q}{d T} d T$ where $\mathrm{dQ} / \mathrm{dT}$ is the change of heat flow with respect to temperature, and $\mathrm{T}_{\mathrm{S}}$ and $\mathrm{T}_{\mathrm{F}}$ are the initial and final temperatures of the MST on heating, respectively. Thermomagnetic curves $\mathrm{M}(\mathrm{H}, \mathrm{T})$ have been acquired using a superconducting quantum interference device (SQUID) magnetometer (by Quantum Design, USA) in high fields and by a Quantum Design PPMS-9T platform in fields of 0.005-0.01 T, respectively, in the temperature interval of 5-400 K. The magnetization isotherms $\mathrm{M}(\mathrm{H})$ were measured in the temperature range 4.2-300 $\mathrm{K}$ with a vibrating sample magnetometer. An Oxford Instruments superconducting solenoid was use for MCE studies in magnetic fields $(\mathrm{H})$ up to 14 
T. The same samples (all with masses of about $200 \mathrm{mg}$ ) were used to measure the magnetization curves and $\Delta \mathrm{T}_{\mathrm{ad}}$. For the direct measurements of the adiabatic change of temperature $\left(\Delta \mathrm{T}_{\mathrm{ad}}\right)$ in fields up to $14 \mathrm{~T}$ in the temperature range of $4.2-350 \mathrm{~K}$, we used the sample extraction technique implemented by Yu. Koshkid'ko and J. Cwik in the experimental setup at the International Laboratory of High Magnetic Fields and Low Temperatures (Wroclaw, Poland), based on a Bitter-type magnet (for details of this setup see Ref. [11]).

A heating rate of $1 \mathrm{~K} / \mathrm{min}$ was used to study the MCE in the vicinity of the transition temperatures for a magnetic field change of $\mu_{0} \Delta \mathrm{H}=14 \mathrm{~T}$. The heating rate was varied in the interval from 7 to $23 \mathrm{~K} / \mathrm{min}$ in order to study the influence of the HR on the MCE of $\mathrm{Ni}_{50} \mathrm{Mn}_{35} \mathrm{In}_{14.25} \mathrm{~B}_{0.75}$ for $\Delta \mathrm{H}=10 \mathrm{~T}$.

\section{Results and discussion}

All samples exhibited magnetization behavior typical for off-stoichiometric In- based Heusler alloys undergoing magnetostructural transitions. The measured $\mathrm{M}(\mathrm{T})$ curves can be characterized by a temperature hysteresis and a jump-like change in magnetization at the direct (austenitic-martensitic: $\mathrm{T}_{\mathrm{AM}}$ ) and inverse (martensitic-austenitic: $\mathrm{T}_{\mathrm{MA}}$ ) martensitic transition temperatures, and the ferromagnetic to paramagnetic transition at the Curie temperature $\left(T_{C}\right)$ in the AP (see Figure 1(a)). The application of magnetic field (shown in Figure 1 for $\mu_{0} \mathrm{H}=5 \mathrm{~T}$ ) results in the temperature stabilization of the ferromagnetic AP and therefore in a shift of the MST temperature to lower temperature (see in Figure 1(a)). The largest shift in $\mathrm{T}_{\mathrm{MA}}$ by about 7.5K/T was detected for $\mathrm{Ni}_{50} \mathrm{Mn}_{35} \mathrm{In}_{14.25} \mathrm{~B}_{0.75}$ (Figure 1). All samples show the ground states in the MP that are characterized by a magnetization of (35-37) emu/g at $5 \mathrm{~K}$ (see in Figure 1 (a) and (b), and the inset). This magnetization value is much lower than that of the AP (see Figure 1 (b) at just above the MST). 
The Curie and MST temperatures obtained at magnetic fields of $0.01 \mathrm{~T}$ and 5T are collected in Table 1 . The values of the total entropy changes $\left(\Delta \mathrm{S}_{\mathrm{t}}\right)$ calculated from the DSC curves (not shown) are listed in Table $1 . \Delta \mathrm{S}_{\mathrm{t}}$ decreases with decreasing MST temperature. The maximum value of $\Delta \mathrm{S}_{\mathrm{t}}$ was observed in the vicinity of the nearly-coupled magnetostructural and ferromagnetic transitions for $\mathrm{Ni}_{50} \mathrm{Mn}_{35} \mathrm{In}_{15}$ (see Table 1). The $\Delta \mathrm{S}_{\mathrm{t}}$ results for all three alloys are in good agreement with the "universal" temperature dependence of $\Delta \mathrm{S}_{\mathrm{t}}(\mathrm{T})$ reported in Ref. [2]. The total entropy changes induced from the application of magnetic field $\left(\Delta \mathrm{S}_{\mathrm{t}}(\mathrm{H}, \mathrm{T})\right)$ can also be determined from isothermal $\mathrm{M}(\mathrm{H})$ curves using the Clausius -Clapeyron-ratio:

$$
\frac{d T}{\mu_{0} d H}=-\frac{\Delta M}{\Delta S_{t}}
$$

where $\frac{d T}{\mu_{0} d H}$ is the derivative of the temperature of the structural transition with respect to the magnitude of the field $\mathrm{H}$, and $\Delta \mathrm{M}$ is the jump in the magnetization resulting from the structural transition. The magnetization behavior of $\mathrm{Ni}_{50.2} \mathrm{Mn}_{34.85} \mathrm{In}_{14.95}$ in the vicinity of the MST was found to be typical for a first order transition (i.e., a metamagnetic transition) induced by magnetic field and can be characterized by a jump in the magnetization when the magnetic field exceeds the critical field of the metamagnetic transition, and by the hysteresis of the magnetization with field (see Figure 2).

The results of the calculations of entropy changes for $\mathrm{Ni}_{50.2} \mathrm{Mn}_{34.85} \mathrm{In}_{14.95}$ for magnetic field changes up to $14 \mathrm{~T}$ are presented in Figure 3. The maximum value of $\Delta \mathrm{S}_{\mathrm{t}}(\mathrm{H}, \mathrm{T})$ obtained using the Clausius - Clapeyron equation was found to be $16.4 \mathrm{~J} /(\mathrm{kg} * \mathrm{~K})$. This result is in good agreement with the value obtained from DSC measurements (see Table 1) but much smaller than that predicted by the "universal" curve of Ref. [2]. Thus, the entropy change $\left(\Delta S_{t}\right)$ must depend not only by the characteristic transition temperature, but also by some other factors. 
The results of direct measurements of the adiabatic temperature change $\Delta \mathrm{T}_{\mathrm{ad}}$ are shown in Figures 4-7. As can be seen from Figure 4, in the vicinity of the MST, $\Delta \mathrm{T}_{\mathrm{ad}}$ increases with the temperature of the MST for large applied magnetic field changes $14 \mathrm{~T}$. The highest values of $\Delta \mathrm{T}_{\text {ad }}$ of about $11 \mathrm{~K}$ were observed for $\mathrm{Ni}_{50} \mathrm{Mn}_{35} \mathrm{In}_{15}$, where the MST happened to be near the Curie temperature. The different values of $\Delta \mathrm{T}_{\mathrm{AD}}$ of $-7 \mathrm{~K}$ for $\Delta \mathrm{H}=20 \mathrm{~T}$ and $6 \mathrm{~T}$ reported in Ref. [4] for $\mathrm{Ni}_{50} \mathrm{Mn}_{35} \mathrm{In}_{15}$ (nominal composition) may be related to the large sensitivity of the MST in In based Heusler alloys to synthesis conditions. The results in Ref. [4] were obtained on samples quenched in water from $800{ }^{\circ} \mathrm{C}$. Plastic deformations of the alloys can also lead to changes in the MST temperatures and MCE values in Heusler alloys [15]. As mentioned earlier, $\Delta \mathrm{S}_{\mathrm{t}}$ shows the same tendency (see Table 1). Thus both $\Delta \mathrm{S}_{\mathrm{t}}$ and $\Delta \mathrm{T}_{\mathrm{ad}}$ increase at the inverse MCE in Ni-Mn-Inbased alloys at the MST as the MST temperature increases. As one can see from Figure 4, the $\Delta \mathrm{T}_{\mathrm{ad}}$ at the second order magnetic phase transitions remains nearly constant for the alloys under investigation.

The $\Delta \mathrm{T}_{\text {ad }}$ saturates in high magnetic fields as shown for $\mathrm{Ni}_{50.2} \mathrm{Mn}_{34.85} \mathrm{In}_{14.95}$ in Figure 5 . The $\Delta \mathrm{T}_{\mathrm{ad}}$ were found to saturate at smaller magnetic fields when the temperature approaches the MST. The maximum, saturated value of $\Delta \mathrm{T}_{\mathrm{ad}}$ of about $6 \mathrm{~K}$ was observed at $\mathrm{H}=5 \mathrm{~T}$ at $283 \mathrm{~K}$ (see Figure 6 (b)). A further increasing of the magnetic field resulted in a broadening of the temperature span of the MCE, however, the onset temperature of $\Delta \mathrm{T}_{\mathrm{ad}}$ remained the same (see Figure 5). It should be noticed for comparison that, in the case of the MCE at the second order phase transition, the field dependence of $\Delta \mathrm{T}_{\mathrm{ad}}$ was well fitted by a $\mathrm{H}^{2 / 3}$ law (see Figure 6 (a)).

It was shown previously [1-4] that the magnitude of the $\Delta \mathrm{T}_{\text {ad }}$ resulting from the MST on heating remains nearly the same for different rates of the pulsed magnetic field. In our case, when the characteristic times of the field change during sample extraction was varied from a few 
fractions of a second to few seconds, the resulting $\Delta \mathrm{T}_{\mathrm{ad}}$ values were also the same and almost identical to those obtained with pulsed magnetic fields (with a pulse duration of several $\mu \mathrm{s}$ ) $[4$, 9]. This means that the transformation to the AP phase during the MST occurs at shorter time scales. On the other hand, the heating rate strongly influences the value of $\Delta \mathrm{T}_{\mathrm{ad}}$. In these prior $\Delta \mathrm{T}_{\mathrm{ad}}$ measurements, the sample was cooled down from $380 \mathrm{~K}$ to $70 \mathrm{~K}$ in zero magnetic field and then heated with different rates up to the same fixed temperature near the MST (246 K). This fixed temperature was the starting temperature for direct measurements of $\Delta \mathrm{T}_{\mathrm{ad}}$, the results of which are shown in Figure 7. An increase in the absolute value of $\Delta \mathrm{T}_{\mathrm{ad}}$ by about $40 \%$ as the heating rate increased from 7 to $23 \mathrm{~K} / \mathrm{min}$ is clear (see Figure 7). A similar but less pronounced effect of the dependence of $\Delta \mathrm{T}_{\mathrm{ad}}$ on the heating rate was reported recently in Ref. [3] for much lower heating rates $(0.05$ and $0.2 \mathrm{~K} / \mathrm{min})$. This effect was also confirmed by the dependence on heat rate of our magnetization data (not shown). One possible origin of this unusual behavior might be rooted in the dynamics of the MST. Indeed, the MST is a first order phase transition and therefore occurs through the nucleation of a new phase via the growth of nuclei. The change in magnetization at an MST strongly depends on the amount of AP in the sample because of the large magnetization of the AP. The fewer the number of nucleation sites of AP phase in the initial state, the larger the jump in the magnetization and, therefore, the MCE values at the MST. Apparently, higher heating rates result in smaller fractions of the ferromagnetic AP in the initial state, and therefore in a larger value of $\Delta \mathrm{T}_{\mathrm{ad}}$. Thus, this effect can be attributed to the existence of a smaller fraction of the ferromagnetic austenite phase in the initial state due to higher heating rates, resulting in a large magnetization jump at the martensitic transformation. 
Since this effect is a consequence of a first order transition, analogous behavior in other magneto-responsive parameters such as resistivity, magnetoresistance, and Hall effect can be expected.

\section{Conclusion}

The adiabatic temperature changes $\left(\Delta \mathrm{T}_{\mathrm{ad}}\right)$ resulting from the phase transitions in Ni-MnIn- based Heusler alloys have been measured using a direct extraction method in magnetic fields up to $14 \mathrm{~T}$. It has been shown that the value of $\Delta \mathrm{T}_{\text {ad }}$ strongly depends on the sample composition, being mostly sensitive to Mn content. The $\Delta \mathrm{T}_{\text {ad }}$ reaches a maximum value when the MST occurs near the Curie temperature of the AP. The values of $\Delta \mathrm{T}_{\mathrm{ad}}$ at the MST do not depend on the rate of the magnetic field change, which ranged from a few fractions of a second to a few seconds, and all results nearly coincided with data obtained with pulse magnetic fields. However, the heating rate of the samples was found to strongly influence the $\Delta \mathrm{T}_{\mathrm{ad}}$ : the faster the sample is heated to its starting temperature near martensitic transition, the higher the value of $\Delta \mathrm{T}_{\mathrm{ad}}$ that is achieved. 


\section{Acknowledgements:}

This work was supported by the Office of Basic Energy Sciences, Material Science Division of the U.S. Department of Energy, DOE Grant No. DE-FG02-06ER46291 (SIU) and DE-FG0213ER46946 (LSU). The authors from Lomonosov Moscow State University acknowledge support from the Russian Foundation for Basic Research (Grant No.15-02-01976). The authors

from International Laboratory of High Magnetic Fields and Low Temperatures, Wroclaw, acknowledge support from the project No.146-MAGNES of the ERA.Net RUS Plus initiative of the EU 7th Framework Programme. E.D. acknowledges support from the grant of Russian Foundation for Basic Research (Grant № 16-32-00905). AG acknowledges partial support from M.V. Lomonosov Moscow State University Program of Development. 


\section{References}

[1] T. Gottschall, K.P. Skokov, F. Scheibel, M. Acet, M. Ghorbani Zavareh, Y. Skourski, J. Wosnitza, M. Farle, O. Gutfleisch, Phys. Rev. Appl. 5, 024013 (2016).

[2] T. Gottschall, K. P. Skokov, D. Benke, M. E. Gruner, and O. Gutfleisch, Phys. Rev. B 93, 184431 (2016).

[3] T. Gottschall, K. P. Skokov, R.Burriel, and O. Gutfleisch, Acta Materialia 107, 1(2016)

[4] M. G. Zavareh, C.S. Mejia, , A.K. Nayak, Y. Skourski, J. Wosnitxa, C. Felser, M. Nicklas, Appl. Phys. Lett. 106, 071904 (2015).

[5] I. Dubenko, A. Quetz, S. Pandey, A.l Arya, Mi. Eubank, I. Rodionov, V. Prudnikov, A. Granovsky, E. Lahderanta, T. Samanta, A. Saleheen, S. Stadler, N. Ali, J. Magn. Magn. Mater. 383, $186(2015)$

[6] A. B. Granovskii,, V. N. Prudnikov, A. P. Kazakov, A. Zhukov, and I. Dubenko, JETP 115 (5), 805 (2012).

[7] I. Dubenko, A. Granovsky, I. Rodionov, E. Lahderanta, M. Kashirin, V.r Makagonov, A. Aryal, A. Quetz, S. Pandey, T. Samanta, S. Stadler, D. Mazumdar, and N. Ali, J. Magn. Magn. Mater. 401, 1145 (2016).

[8] J. Liu, T. Gottschall, K.P. Skokov, O. Gutfleisch, Nat. Mater. 11, 620 (2012).

[9] T. Kihara, X. Xu, W. Ito, R. Kainuma, M. Tokunaga, Phys. Rev. B 90, 214409 (2014).

[10] A. Quetz, Yu. S. Koshkid'ko, I. Titov, I. Rodionov, S. Pandey, A. Aryal, P. J. IbarraGaytan, V. Prudnikov, A. Granovsky, I. Dubenko, T. Samanta , J. Cwik, J. L.S. Lamazares, S. Stadler, E. Lahderanta, N. Ali, J. Alloys and Compounds 683, 139 (2016). 
[11] I. D. Rodionov, Yu. S. Koshkid'ko, J. Cwik, A. Quetz, S. Pandey, A. Aryal,I. S. Dubenko, S. Stadler, N. Ali, I. S. Titov, M. Blinov, M. V. Prudnikova, V. N. Prudnikov, E. Lähderanta, and A. B. Granovskii, JETP Letters, 101, No. 6, 385 (2015).

[12] V. V. Khovaylo, K. P. Skokov, Yu. S. Koshkid'ko, V. V. Koledov, V. G. Shavrov, V. D. Buchelnikov, S. V. Taskaev, H. Miki, T. Takagi, and A. N. Vasiliev, Phys. Rev. B 78, 060403 (2008).

[13] W. Ito, Y. Imano, R. Kainuma, Y. Sutou, K. Oikawa, and K. Ishida, Metall. Mater. Trans. A 38, 759 (2007).

[14] S. Pandey, A. Quetz, I. D. Rodionov, A. Aryal, M. I. Blinov, I. S. Titov, V. N. Prudnikov, A. B. Granovsky, I. Dubenko, S. Stadler, and N. Ali, Journal of Applied Physics 117, 183905 (2015).

[15] P. Álvarez-Alonso, C. O. Aguilar-Ortiz, J. P. Camarillo, D. Salazar, H. Flores-Zúñiga, and V. A. Chernenko, Appl. Phys. Lett. 109, 212402 (2016). 
Table 1: The Heusler alloy compositions, the phase transition temperatures of the MST taken on cooling $\left(\mathrm{T}_{\mathrm{AM}}\right)$ and heating $\left(\mathrm{T}_{\mathrm{MA}}\right)$, and $\mathrm{T}_{\mathrm{C}}$ of the AP at $\mathrm{H}=0.01$, $\mathrm{T}$ and $\Delta \mathrm{T}_{\mathrm{ad}}$ of the MST obtained from direct measurements, $\Delta \mathrm{S}_{\mathrm{t}}$ determined from DSC measurements, and isothermal $M(H)$ curves using Clausius- Clapeyron relation.

\begin{tabular}{|l|c|c|c|c|c|c|c|}
\hline$\#$ & Nominal composition & $\begin{array}{c}\mathrm{T}_{\mathrm{AM}}{ }^{0.01 \mathrm{~T}} / \mathrm{T}_{\mathrm{AM}}{ }^{5 \mathrm{~T}} \\
{[\mathrm{~K}]}\end{array}$ & $\begin{array}{c}\mathrm{T}_{\mathrm{MA}}{ }^{0.01 \mathrm{~T}} / \mathrm{T}_{\mathrm{MA}}{ }^{5 \mathrm{~T}} \\
{[\mathrm{~K}]}\end{array}$ & $\begin{array}{c}\mathrm{T}_{\mathrm{C}} \\
{[\mathrm{K}]}\end{array}$ & $\begin{array}{c}\Delta \mathrm{S}_{\mathrm{t}}(\mathrm{DSC}) \\
{[\mathrm{J} /(\mathrm{kg} \cdot \mathrm{K})]}\end{array}$ & $\begin{array}{c}\Delta \mathrm{S}_{\mathrm{t}}[\mathrm{J} /(\mathrm{kg} \bullet \mathrm{K})] \\
(\text { Clausius- } \\
\text { Clapeyron } \\
\text { relation })\end{array}$ & $\begin{array}{c}\Delta \mathrm{T}_{\mathrm{ad}}[\mathrm{K}] \\
\left(\mu_{0} \Delta \mathrm{H}=14 \mathrm{~T}\right)\end{array}$ \\
\hline $\mathrm{N} 1$ & $\mathrm{Ni}_{50} \mathrm{Mn}_{35} \mathrm{In}_{15}$ & $312 / 310$ & $319 / 316$ & 313 & 34.0 & 29.5 & -11 \\
\hline $\mathrm{N} 2$ & $\mathrm{Ni}_{50.2} \mathrm{Mn}_{34.85} \mathrm{In}_{14.95}$ & $287 / 267$ & $293 / 274$ & 320 & 19.8 & 16.4 & -6 \\
\hline $\mathrm{N} 3$ & $\mathrm{Ni}_{50} \mathrm{Mn}_{35} \mathrm{In}_{14.25} \mathrm{~B}_{0.75}$ & $245 / 205$ & $264 / 229$ & 324 & 9.5 & 4.5 & -3 \\
\hline
\end{tabular}




\section{Figures Captions}

Figure 1. (a) The $M(T)$ curves of $\mathrm{Ni}_{50} \mathrm{Mn}_{35} \mathrm{In}_{14.25} \mathrm{~B}_{0.75}$ and $\mathrm{Ni}_{50.2} \mathrm{Mn}_{34,85} \mathrm{In}_{14.95}$ obtained with increasing/decreasing temperature ((closed symbols)/(open symbols)) in magnetic fields $0.01 \mathrm{~T}$. The arrows show the phase transition temperatures. (b) The M(T) curves for Ni-Mn-In-based Heusler alloys with increasing/decreasing temperature ((closed symbols)/(open symbols)) at a magnetic field of $5 \mathrm{~T}$. Inset: The $\mathrm{M}(\mathrm{H})$ curve of $\mathrm{Ni}_{50} \mathrm{Mn}_{35} \mathrm{In}_{14.25} \mathrm{~B}_{0.75}$ obtained at $\mathrm{T}=5 \mathrm{~K}$.

Figure 2. Characteristic magnetization isotherms of $\mathrm{Ni}_{50.2} \mathrm{Mn}_{34.85} \mathrm{In}_{14.95}$ (symbols lines are guides for the eye). The sample was cooled from $380 \mathrm{~K}$ to $10 \mathrm{~K}$ at zero magnetic field prior to the measurements.

Figure 3. Magnetic entropy changes of $\mathrm{Ni}_{50.2} \mathrm{Mn}_{34.85} \mathrm{In}_{14.95}$ induced by magnetic fields changes $(\Delta \mathrm{H})$ near the MST (estimated from the Clausius -Clapeyron relation).

Figure 4. The temperature dependencies of the adiabatic temperature change for some Ni-MnIn-based alloys obtained at $\Delta \mu_{0} \mathrm{H}=14 \mathrm{~T}$.

Figure 5. The adiabatic temperature changes of $\mathrm{Ni}_{50.2} \mathrm{Mn}_{34.85} \mathrm{In}_{14.95}$ as a function of temperature for different $\Delta \mathrm{H}$ values.

Figure 6. Adiabatic temperature changes obtained for $\mathrm{Ni}_{50.2} \mathrm{Mn}_{34.85} \mathrm{In}_{14.95}$ in magnetic fields up to $14 \mathrm{~T}$ near (a) $\mathrm{T}_{\mathrm{C}}$ and (b) the MST.

Figure 7. The adiabatic temperature changes obtained for $\mathrm{Ni}_{50} \mathrm{Mn}_{35} \mathrm{In}_{14.25} \mathrm{~B}_{0.75}$ with $\mu_{0} \Delta \mathrm{H}=10 \mathrm{~T}$ at different heating rates with starting temperature $\mathrm{T}=246 \mathrm{~K}$. 


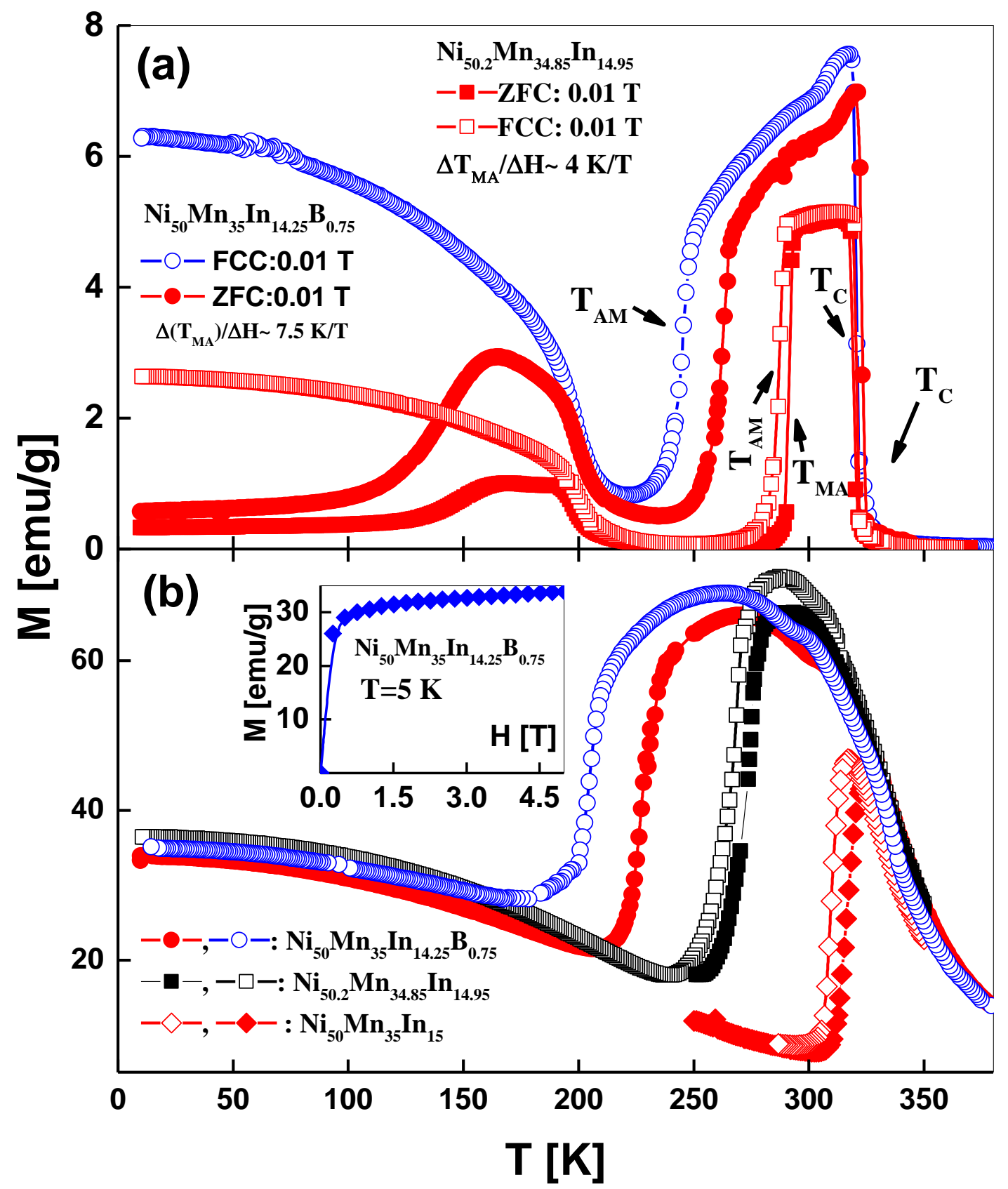

Figure 1. (a) The $M(T)$ curves of $\mathrm{Ni}_{50} \mathrm{Mn}_{35} \mathrm{In}_{14.25} \mathrm{~B}_{0.75}$ and $\mathrm{Ni}_{50.2} \mathrm{Mn}_{34,85} \mathrm{In}_{14.95}$ obtained with increasing/decreasing temperature ((closed symbols)/(open symbols)) in magnetic fields $0.01 \mathrm{~T}$. The arrows show the phase transition temperatures. (b) The M(T) curves for Ni-Mn-In-based Heusler alloys with increasing/decreasing temperature ((closed symbols)/(open symbols)) at a magnetic field of $5 \mathrm{~T}$. Inset: The $\mathrm{M}(\mathrm{H})$ curve of $\mathrm{Ni}_{50} \mathrm{Mn}_{35} \mathrm{In}_{14.25} \mathrm{~B}_{0.75}$ obtained at $\mathrm{T}=5 \mathrm{~K}$. 


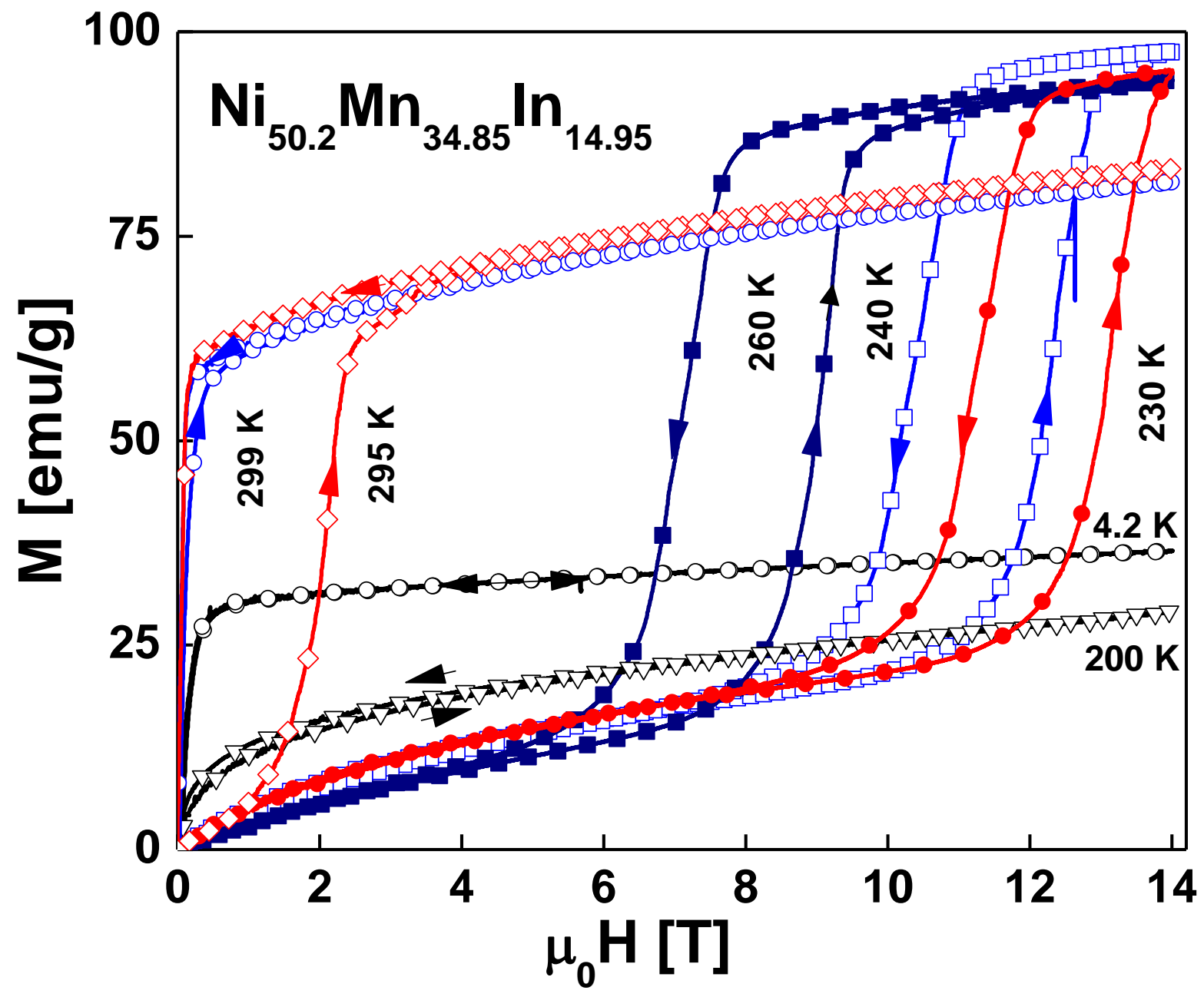

Figure 2. Characteristic magnetization isotherms of $\mathrm{Ni}_{50.2} \mathrm{Mn}_{34.85} \mathrm{In}_{14.95}$ (symbols lines are guides for the eye). The sample was cooled from $380 \mathrm{~K}$ to $10 \mathrm{~K}$ at zero magnetic field prior to the measurements. 


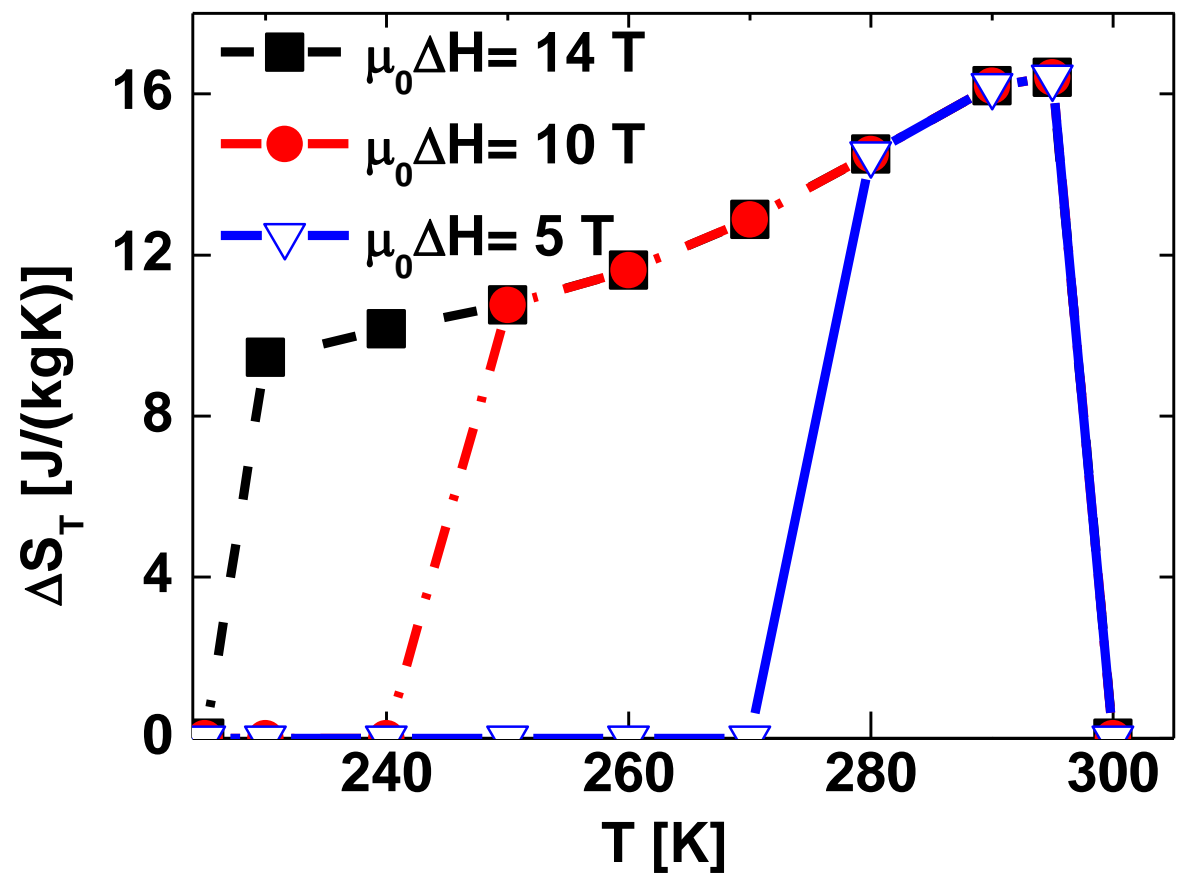

Figure 3. Magnetic entropy changes of $\mathrm{Ni}_{50.2} \mathrm{Mn}_{34.85} \mathrm{In}_{14.95}$ induced by magnetic fields changes $(\Delta \mathrm{H})$ near the MST (estimated from the Clausius -Clapeyron relation). 


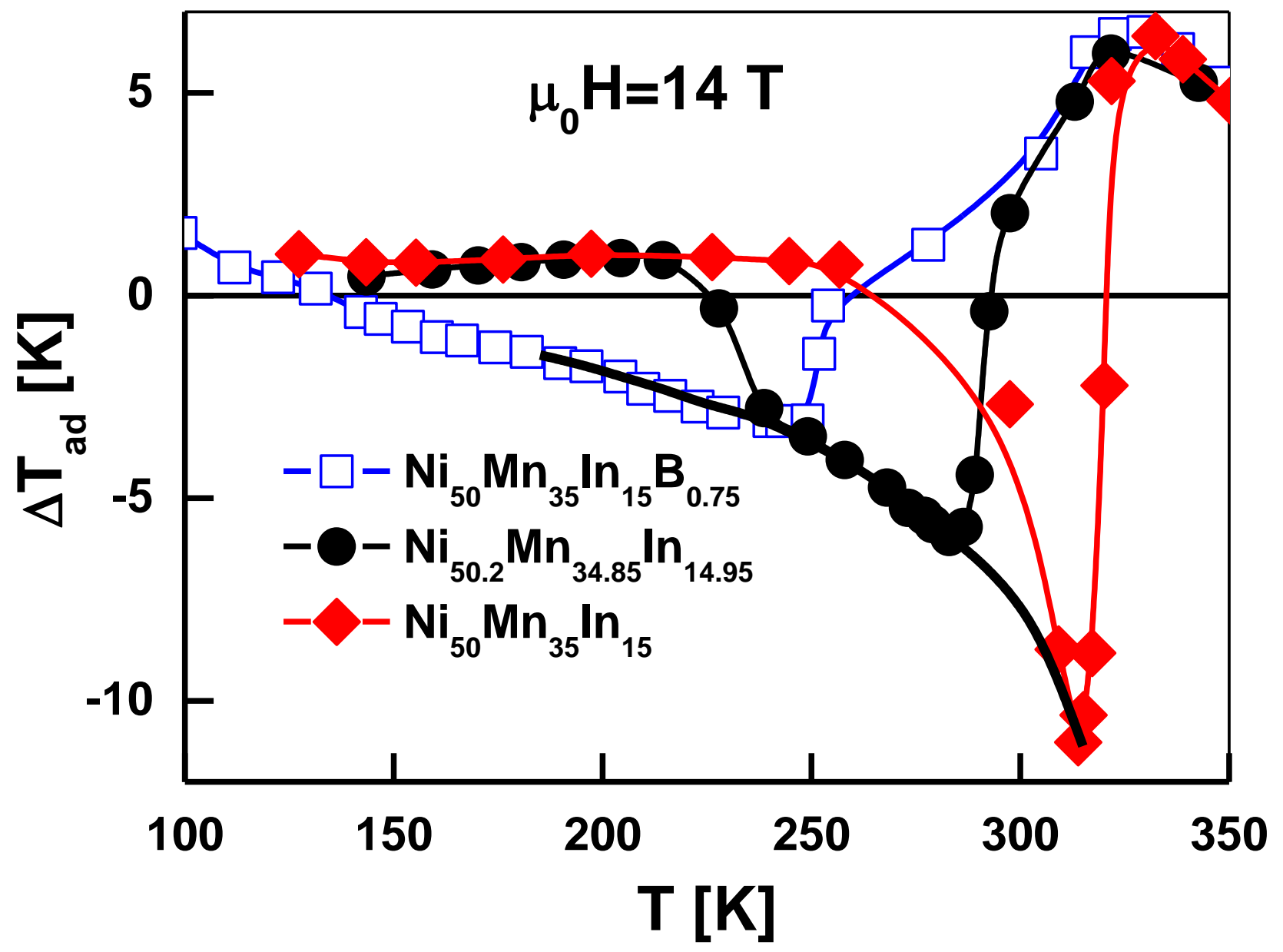

Figure 4. The temperature dependencies of the adiabatic temperature change for some Ni-MnIn-based alloys obtained at $\Delta \mu_{0} \mathrm{H}=14 \mathrm{~T}$. 


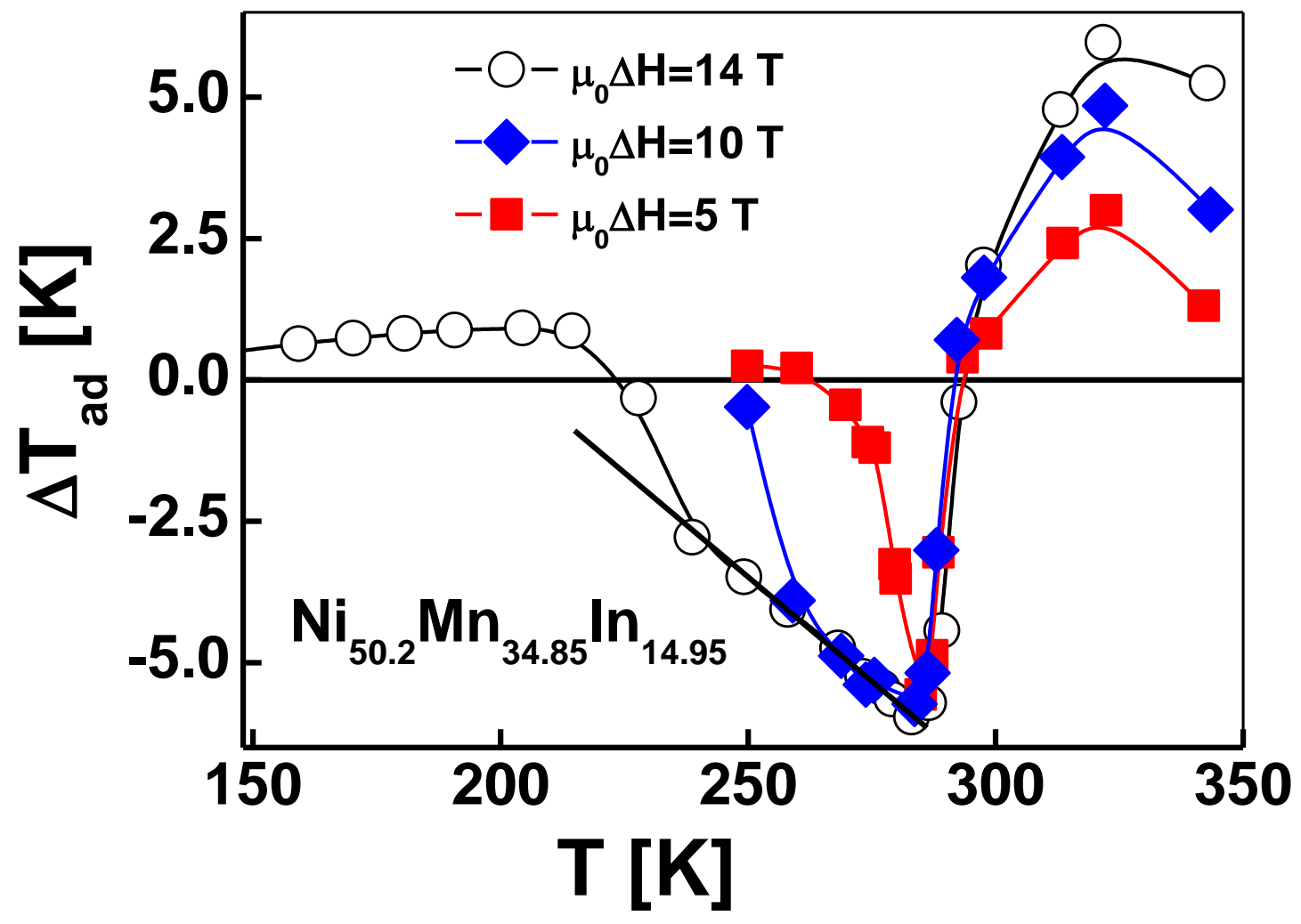

Figure 5. The adiabatic temperature changess of $\mathrm{Ni}_{50.2} \mathrm{Mn}_{34.85} \mathrm{In}_{14.95}$ as a function of temperature for different $\Delta \mathrm{H}$ values. 


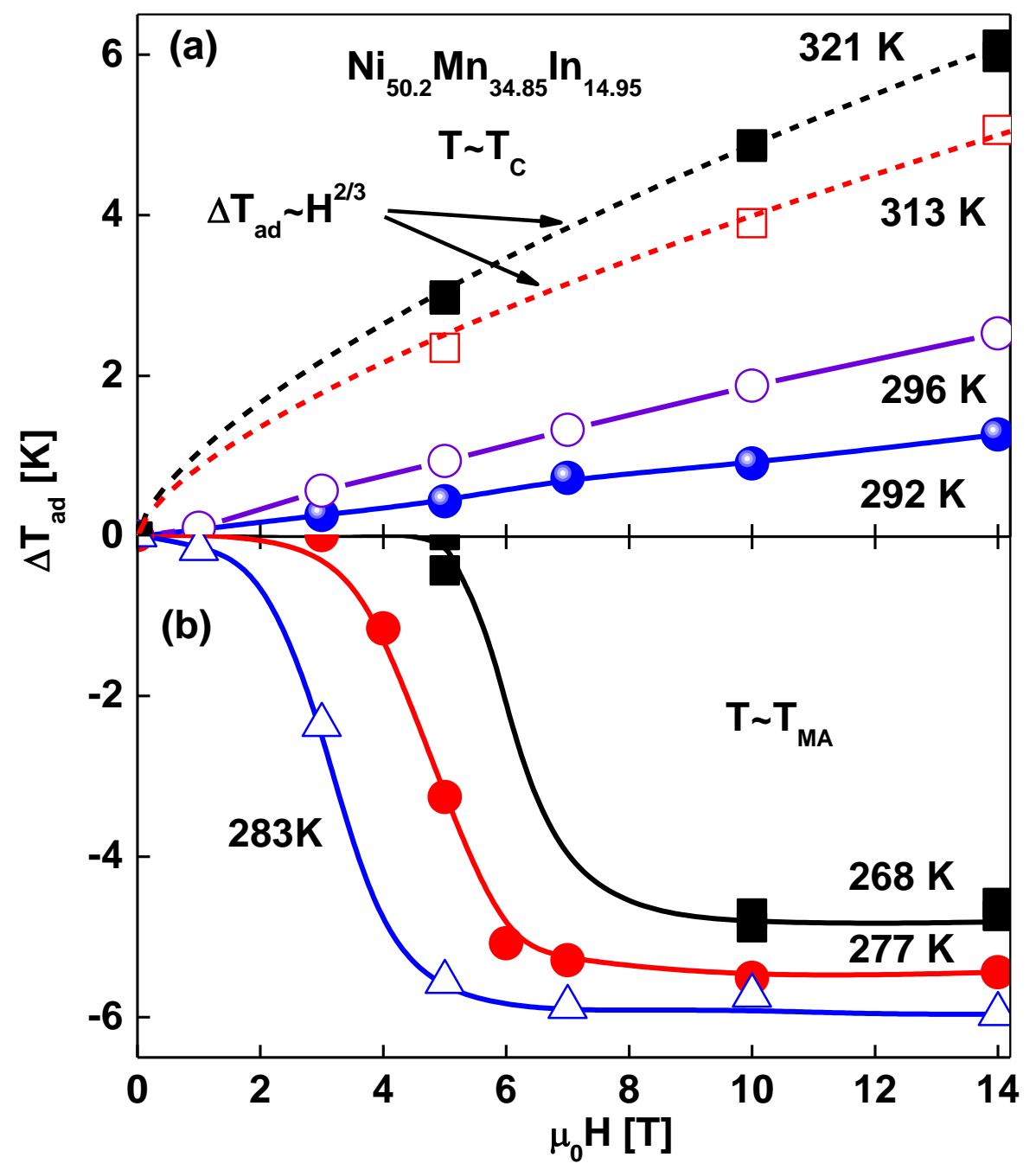

Figure 6. Adiabatic temperature changes obtained for $\mathrm{Ni}_{50.2} \mathrm{Mn}_{34.85} \mathrm{In}_{14.95}$ in magnetic fields up to $14 \mathrm{~T}$ near (a) $\mathrm{T}_{\mathrm{C}}$ and (b) the MST. 


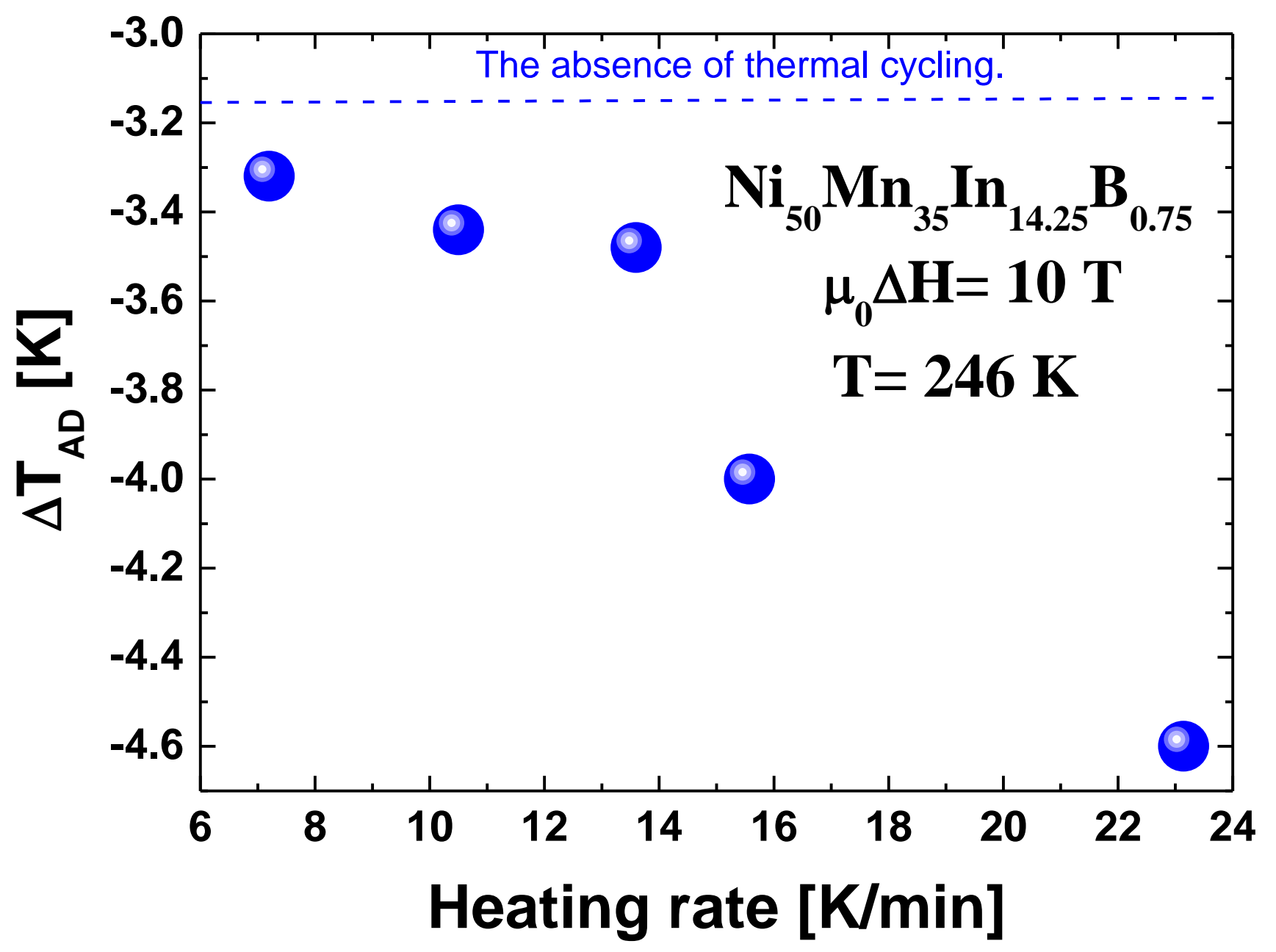

Figure 7. The adiabatic temperature changes obtained for $\mathrm{Ni}_{50} \mathrm{Mn}_{35} \mathrm{In}_{14.25} \mathrm{~B}_{0.75}$ with $\mu_{0} \Delta H=10 \mathrm{~T}$ at different heating rates with starting temperature $\mathrm{T}=246 \mathrm{~K}$. 